\title{
A COMPARATIVE STUDY OF THE RURAL FAMILY LIVING ADAPTATION WITHIN THE FRAME WORK OF CLIMATE CHANGE IN A NEWLY RECLAIMED AND COMMUNITY AND A TRADITIONAL COMMUNITY IN MINYA GOVERNORATE El Said, Mervat S. A. rural woman Dept., Agric. Extension and Rural Development Res. inst.
}
دراسة مقارنة للتكيف المعيشى للأسرة الريفية فى ظل التغيرات المناخية فى مجتمع

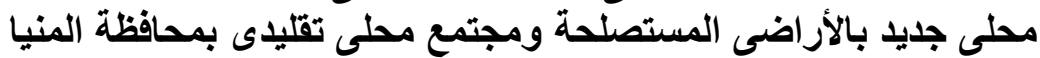

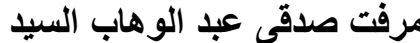 قسم بحوث ترشيد المرأة الريفية بمعهل بحوث الأرشـاد الزراعى والتتمية الريفية بمركز البحوث الزراعية
المستخلص

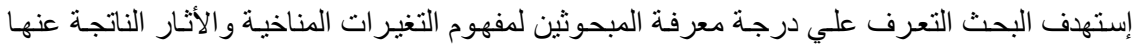

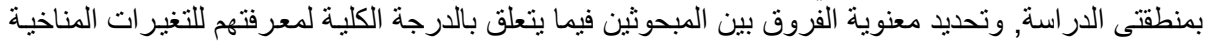

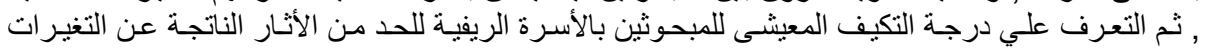

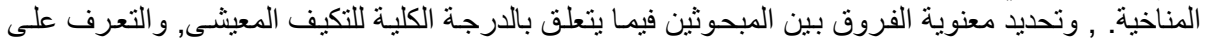

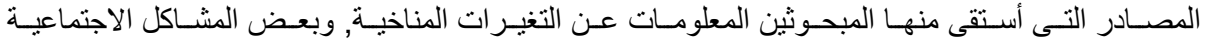

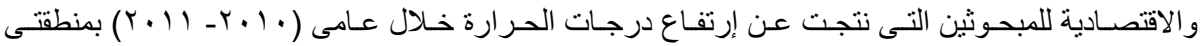
الدر اسة.

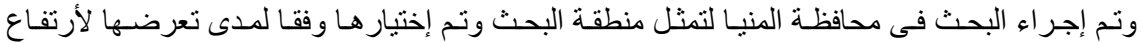

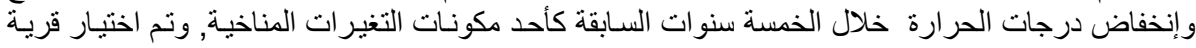

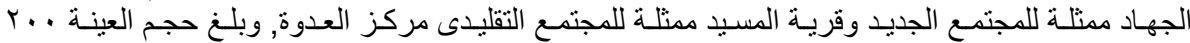

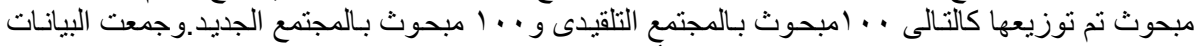

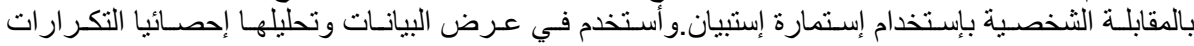

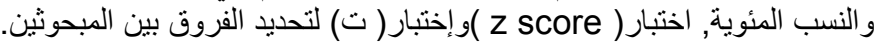
وتلخصت أهم النتائج فيما يلي: الني:

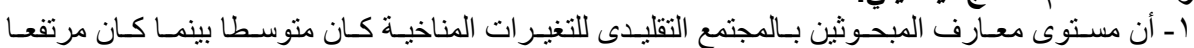

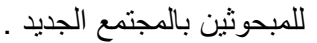

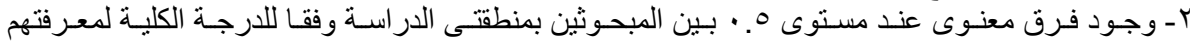
بالتغير ات المناخية و وإثار ها.

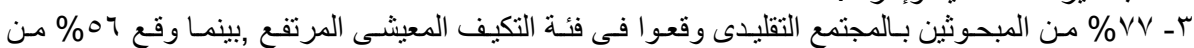

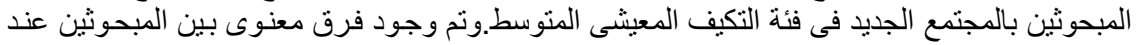

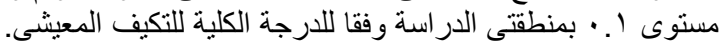

المقدمة والمثكلة البحثية

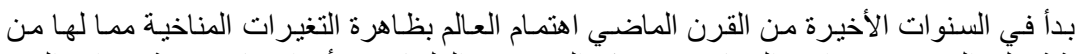

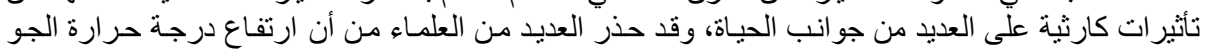

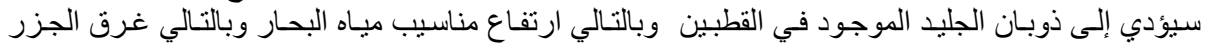

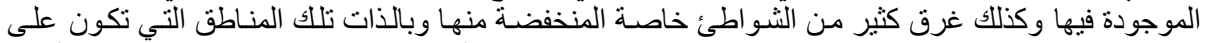

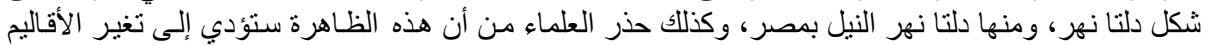

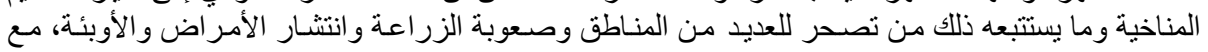
إمكانية تغير فصول السنة ذاتها وتبدلها، مع ملاحظة اثر ذللك على المحاصيل الزئ الزعة اعية بالتحديد. 
El Said, Mervat S. A.

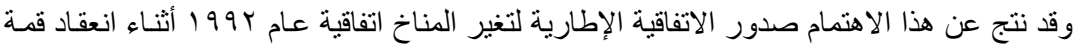

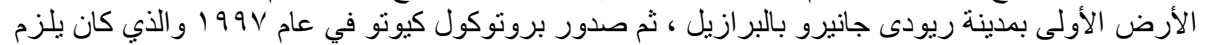

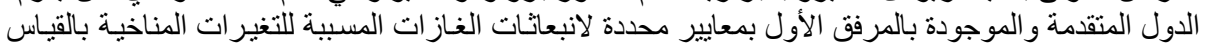

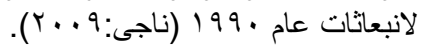

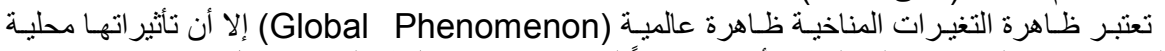

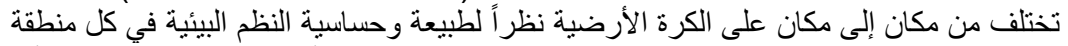

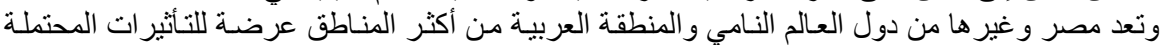

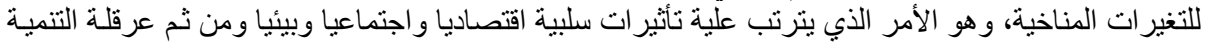

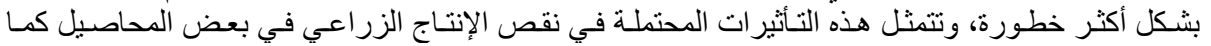

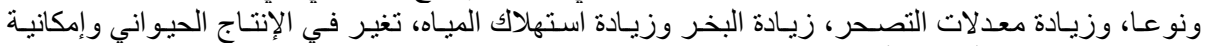

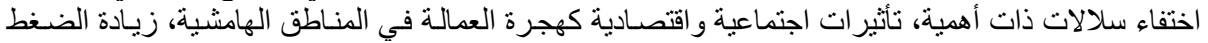

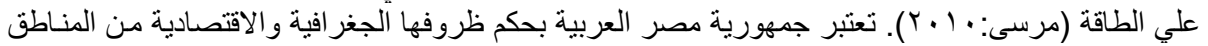

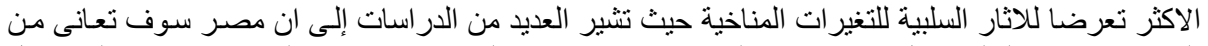

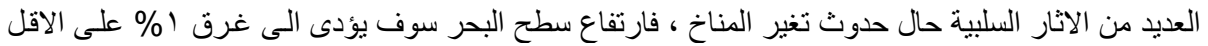

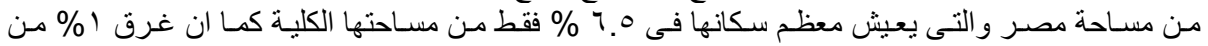

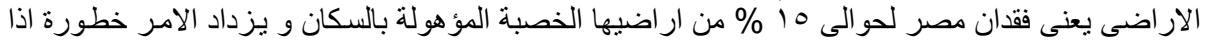

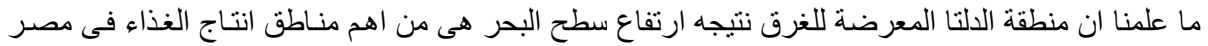

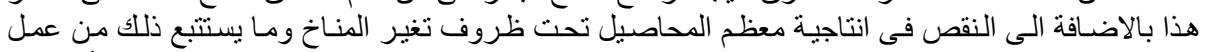

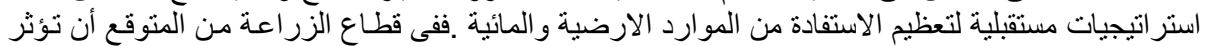

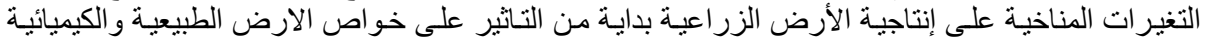

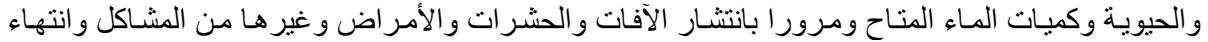

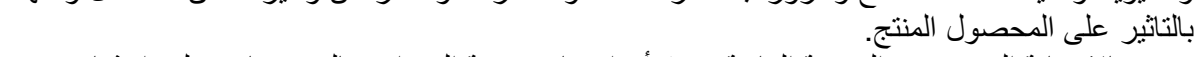

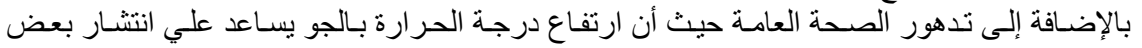

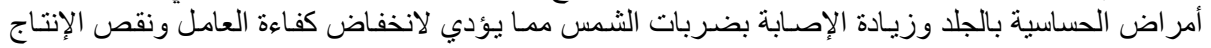

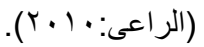

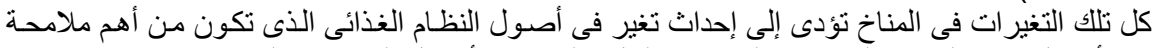

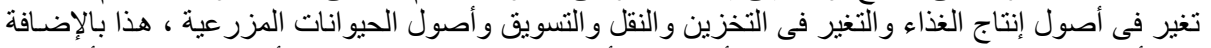

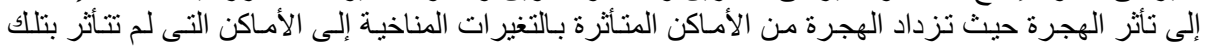

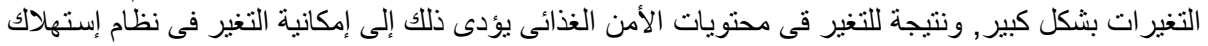

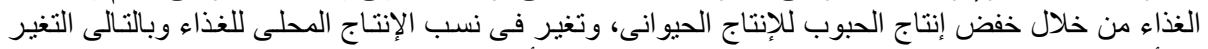

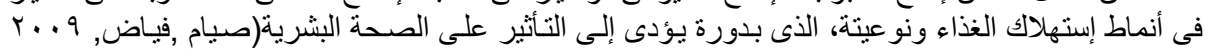

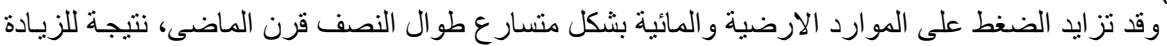

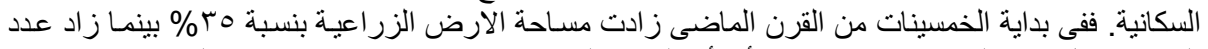

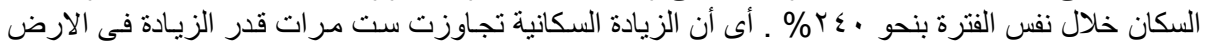

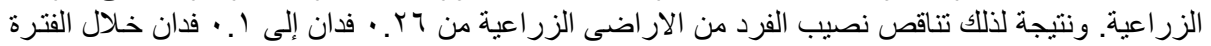

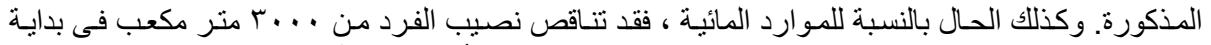

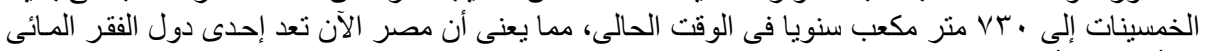

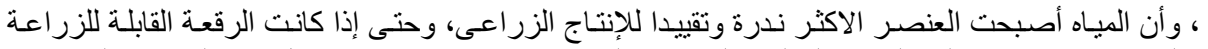

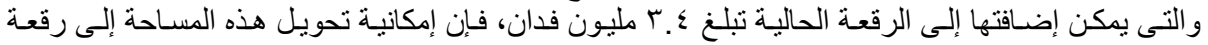
زراعية تتوقف على الموارد المائية المتاحة.

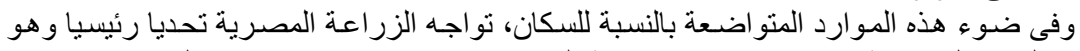

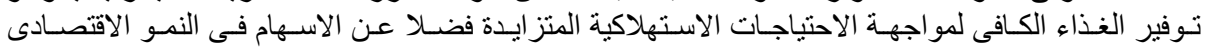

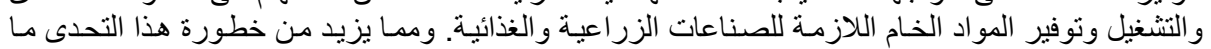

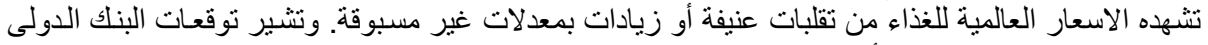

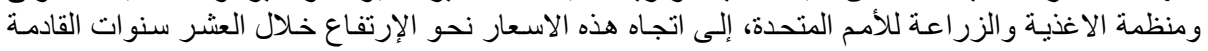

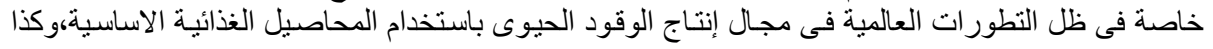




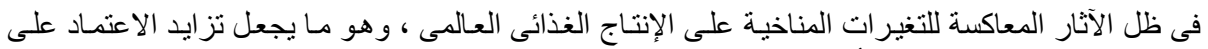

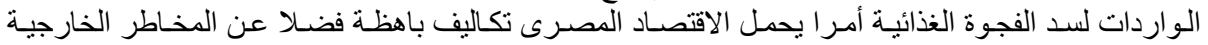

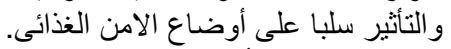

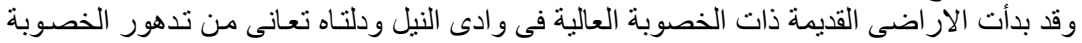

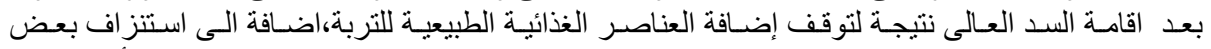

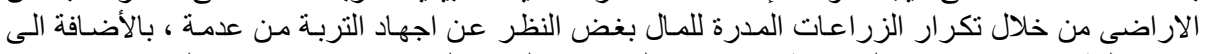

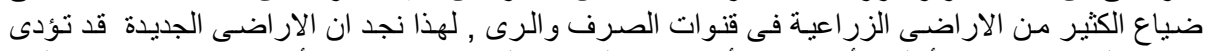

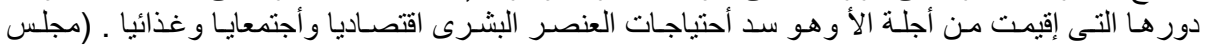

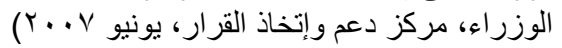

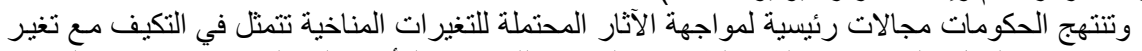

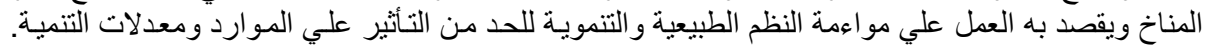

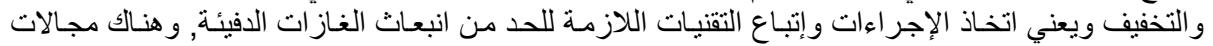

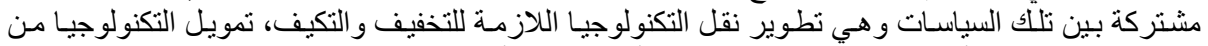

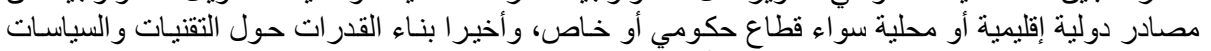

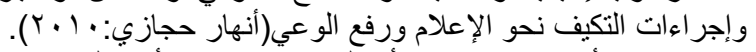

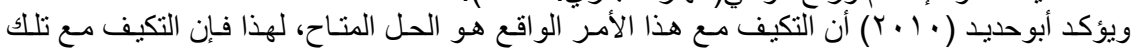

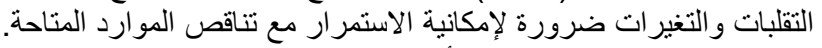

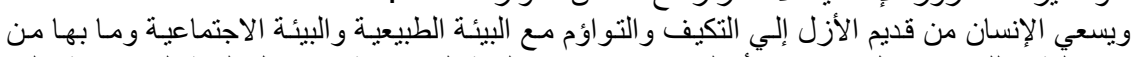

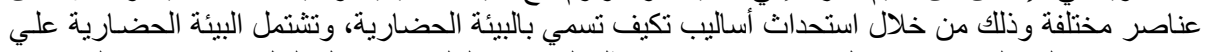

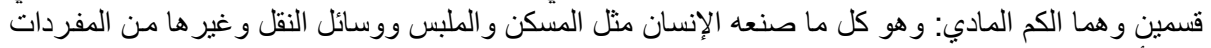

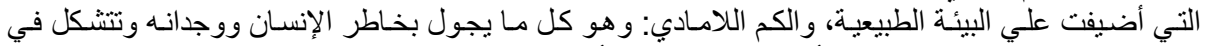

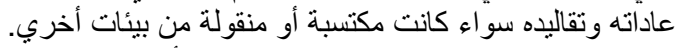

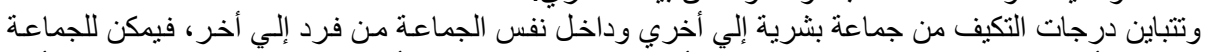

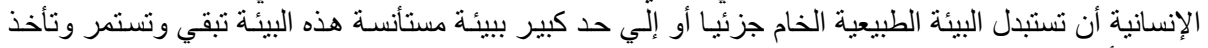

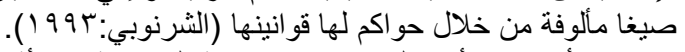

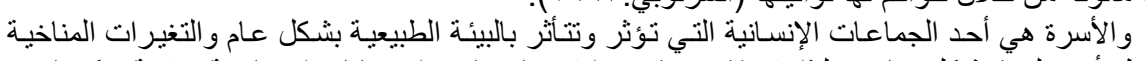

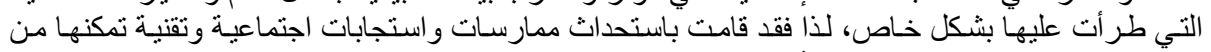

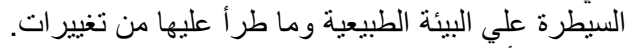

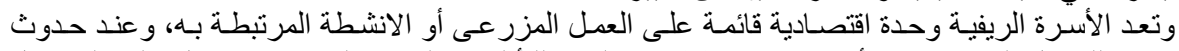

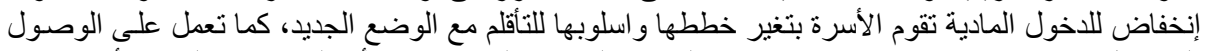

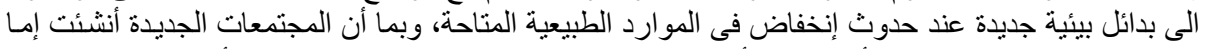

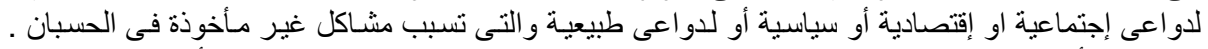

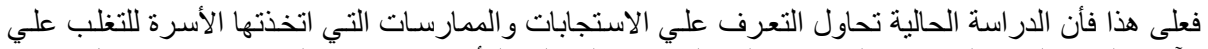

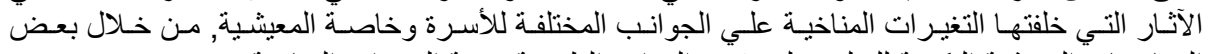

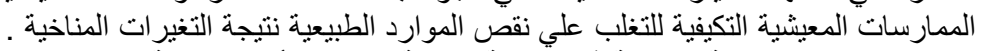

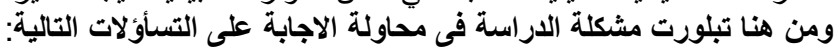

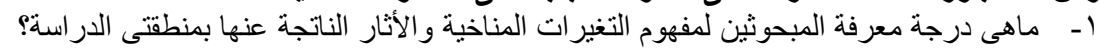

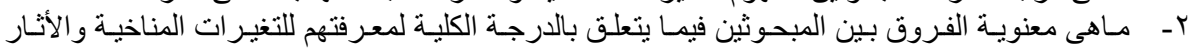

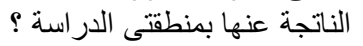

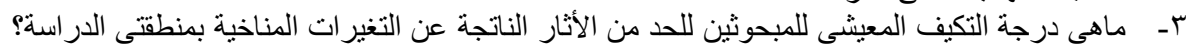

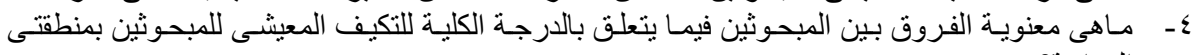

الدراسة؟ ماهى معنج

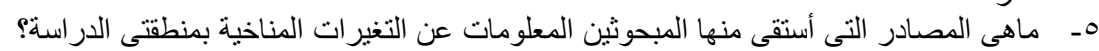

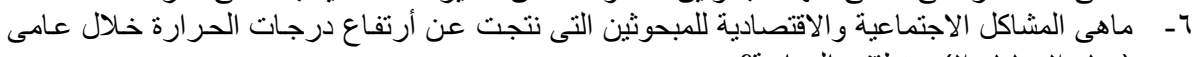

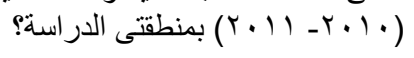


El Said, Mervat S. A.

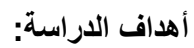

ا. التعرف علي درجة معرفة المبحوثين لمفهوم التغيرات المناخية والأثار الناتجة عنها بمنطقتى الدراسة.

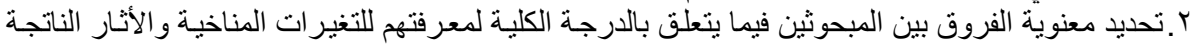

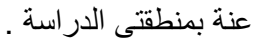
آـ التعرف علي درجة التكيف المعيثى للمبحوثين للحد من الأثار الناتجة عن التغيرات المناخية بمنطقى

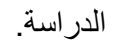

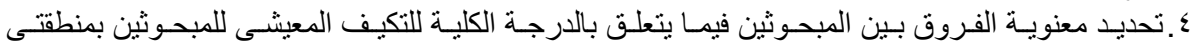
الأسة.

هـ التعرف على العصادر النى أستقى منها المبحوثين المعلومات عن التغيرات المناخية بمنطقتى الدراسة.

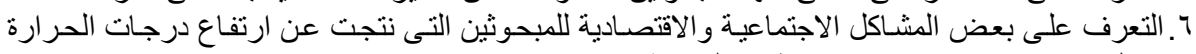

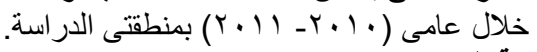

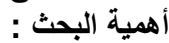

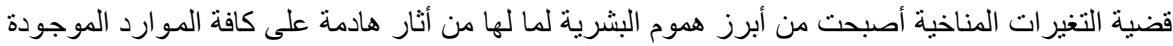

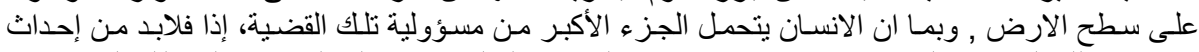

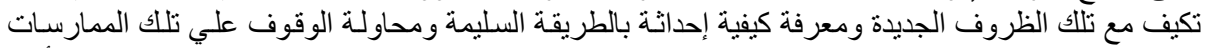

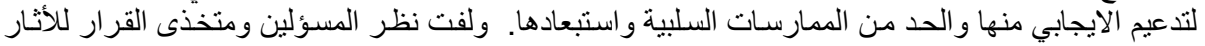

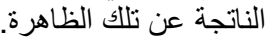

الفروض البحثية : لتحقيق هدفى البحث الثانى والر ابع تم صياغة الفروض البحثية التالية:

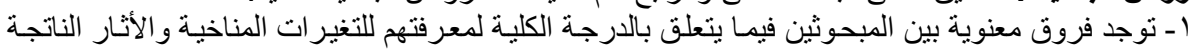
عنها بمنطقتى الدراسة.

ז- توجد فروق معنوية بين المبحوثين فيما يتعلق يتعلق بالدرجة الكلية للتكيف المعيثى بمنطقتى الدراسة.

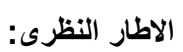

التغير ات المناخية هى أى تغير جوهرى فى مقاييس المناخ ـ مثل الحرارة، البخر، أو الرياح ـ يمتد لفترة

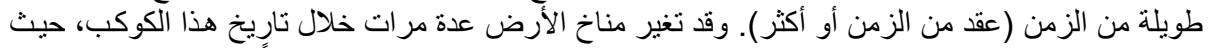

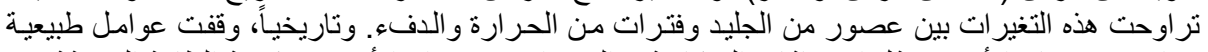

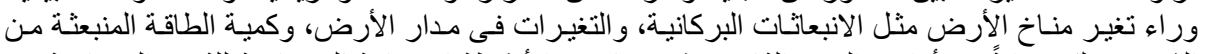

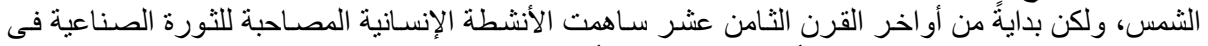

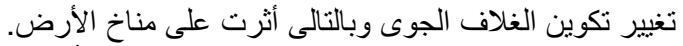

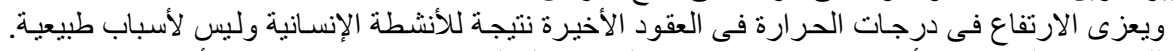

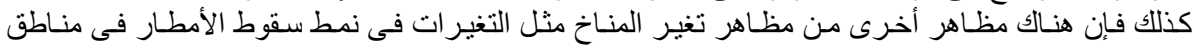

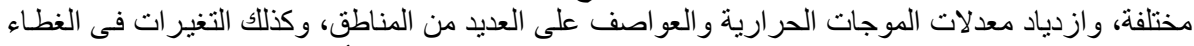

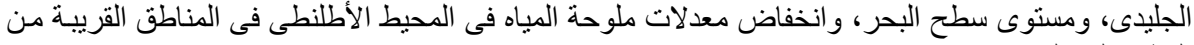

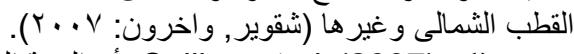

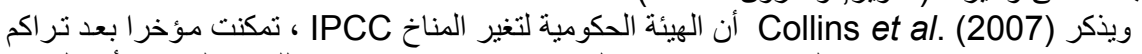

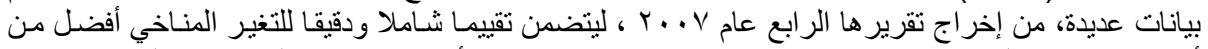

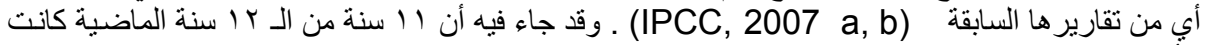

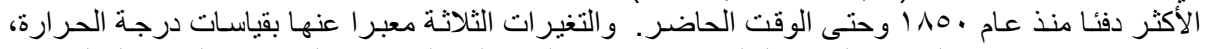

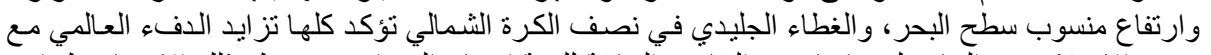

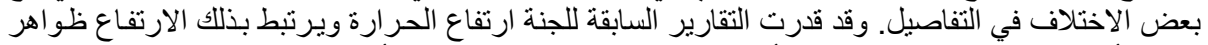

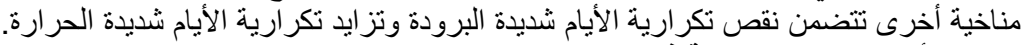

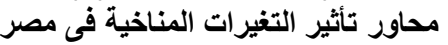

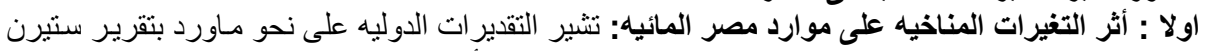

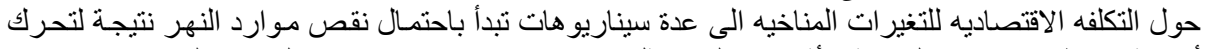

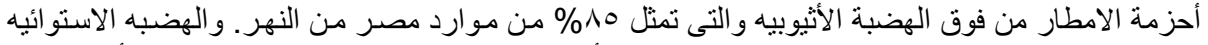

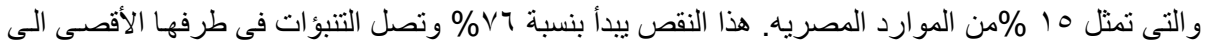




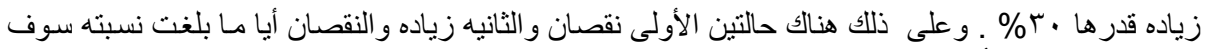

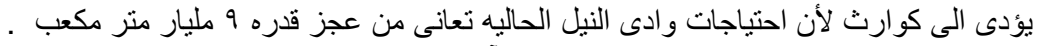

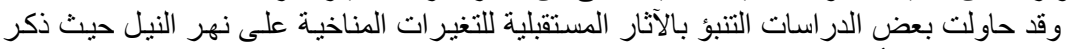

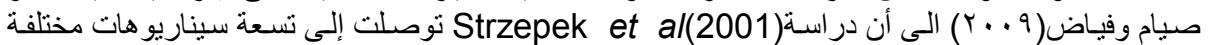

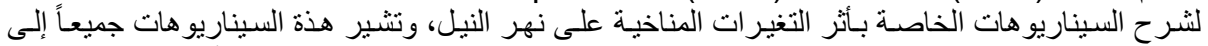

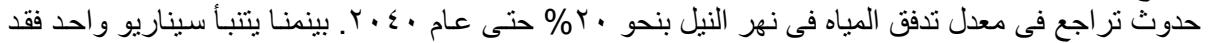

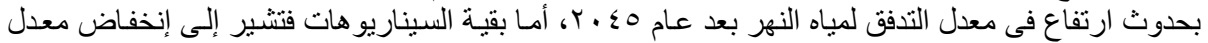

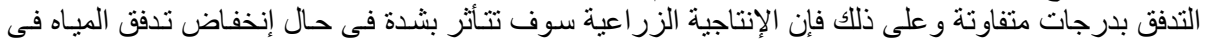

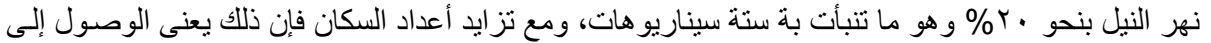

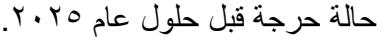

ثانيا: أثر التغيرات المناخية على النئ الإنتاجية الفدانية:

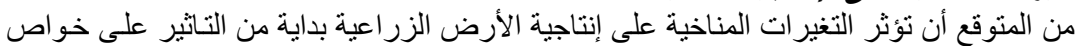

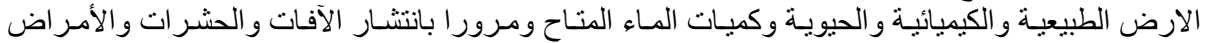

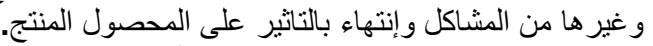

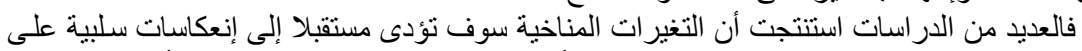

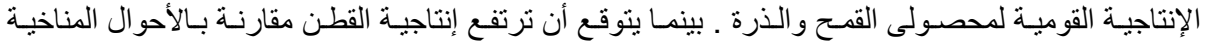

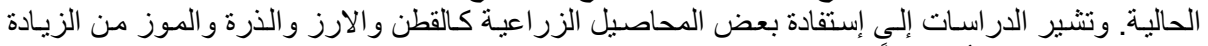

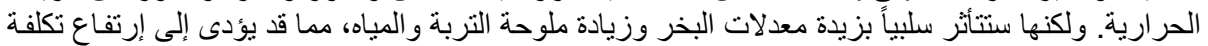

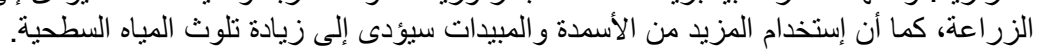

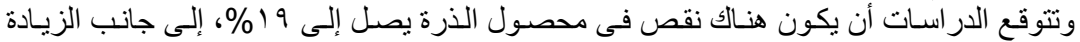

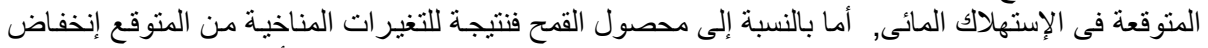

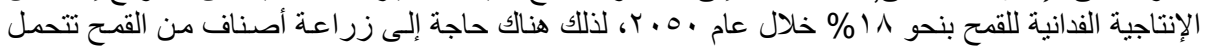

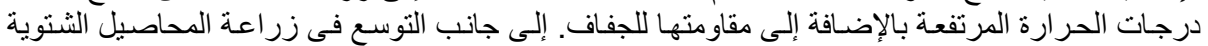

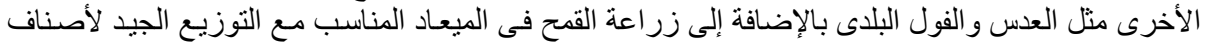

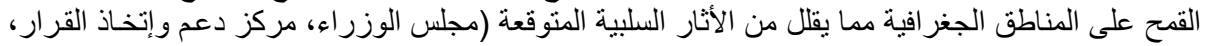

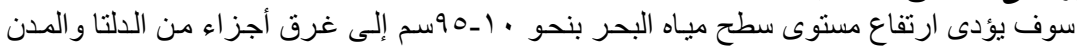

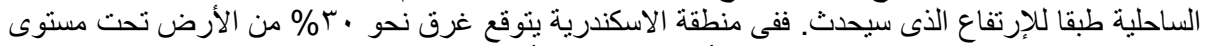

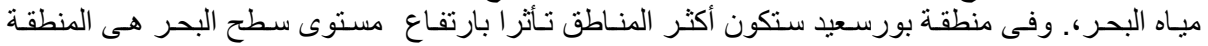

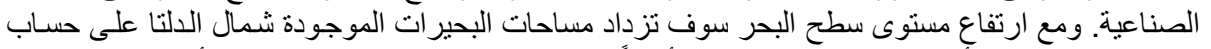

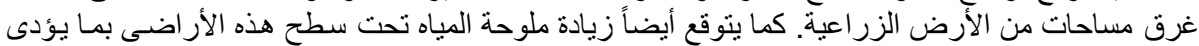

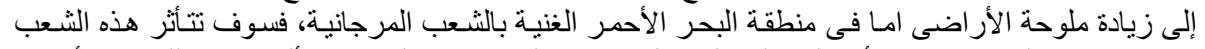

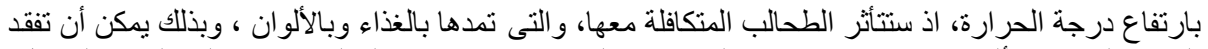

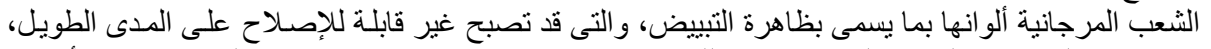

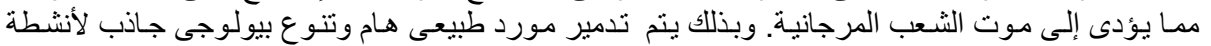

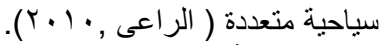
طرق مواجهة ظاهرة التغيرات المنات المناخية

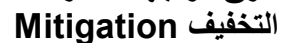

ويُقصد به الحد من انبعانات غاز ات الاحتباس الحبات الحر اري من مختلف القطاعات عن طريق استخدام

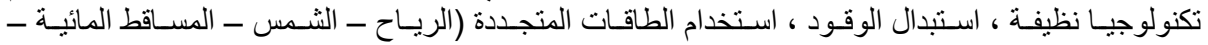

Adaptation التكيف 
El Said, Mervat S. A.

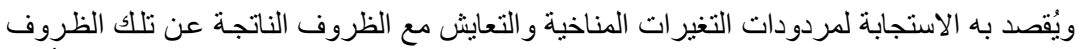

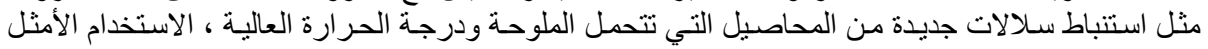

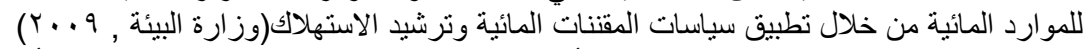

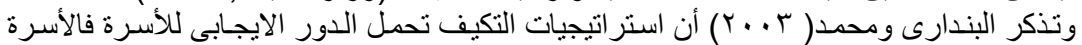

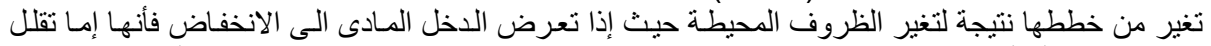

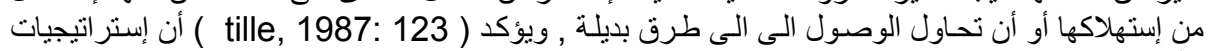

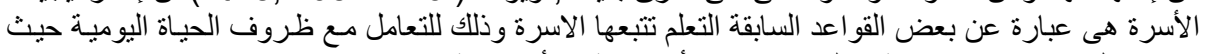

تعد وسائل تتخذها الاسرة تؤثر على على قرار اتها الأجتماعية والأقتصادية.

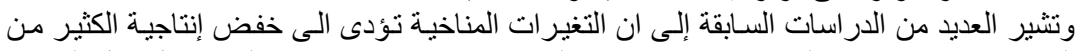

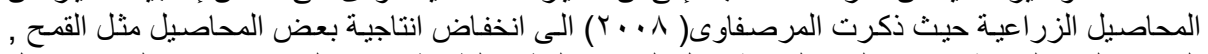

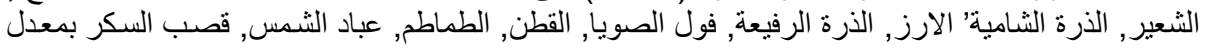

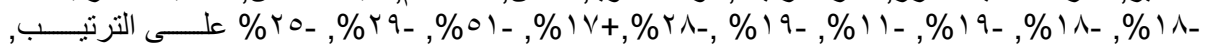

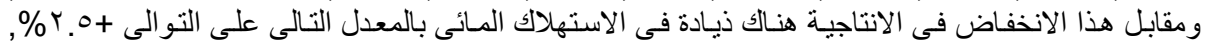

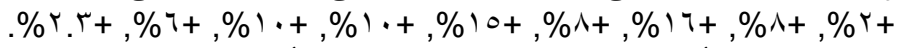

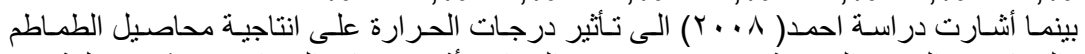

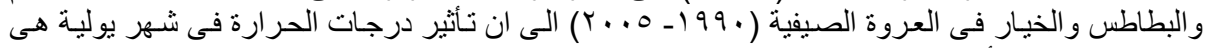

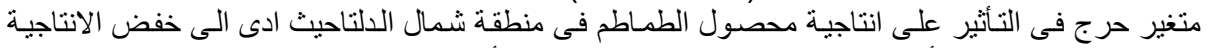

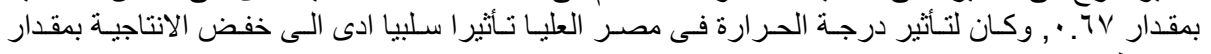
. 19

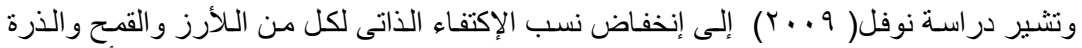

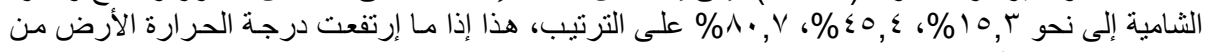

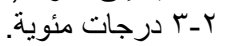

\section{الطريقة البحثية}

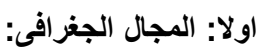

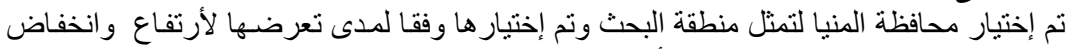

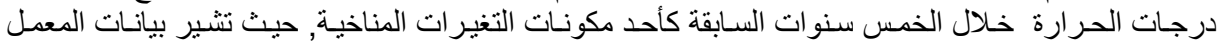

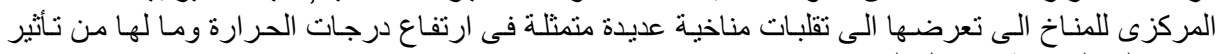

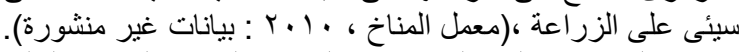

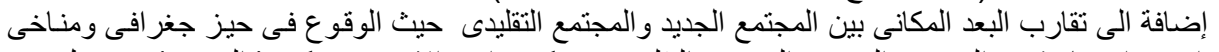

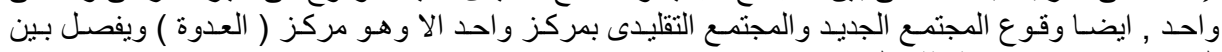
المجتمعين مايقرب من ثلاثة كيلو مترات البخات.

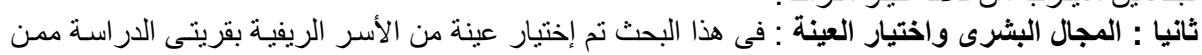

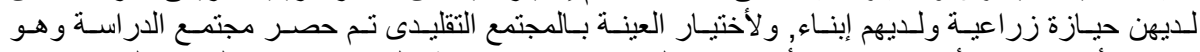

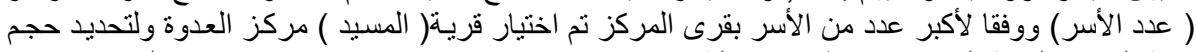

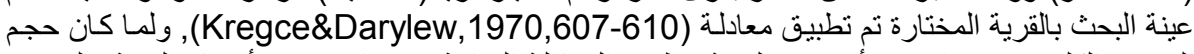

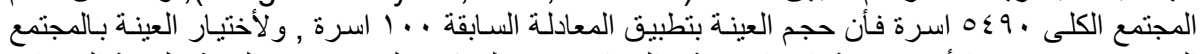

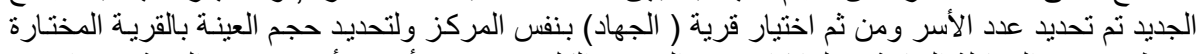

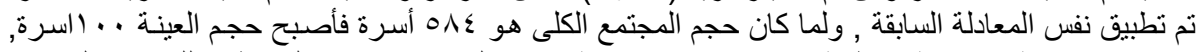

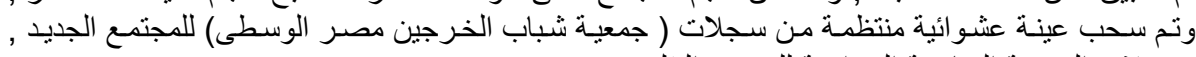
وسجلات الجمعية التعاونية الزر اعية للمجتمع التقليدى.

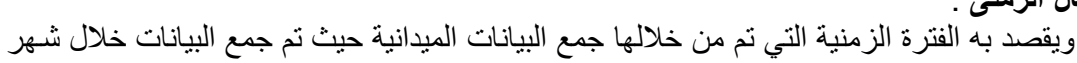

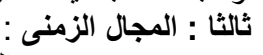

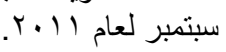

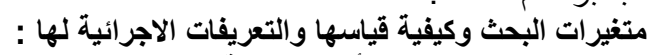

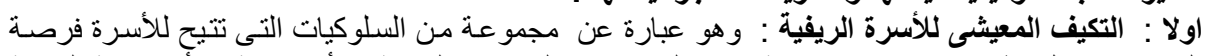

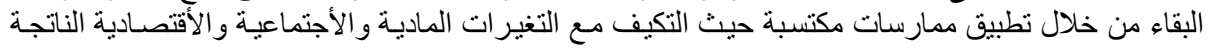




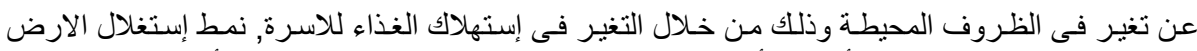

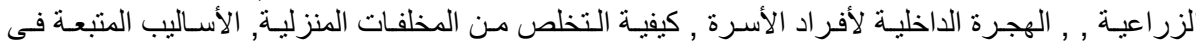

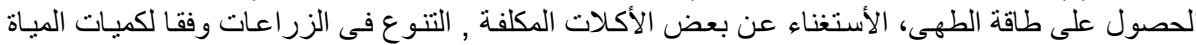

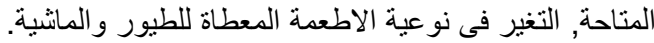

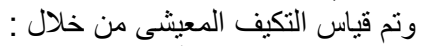

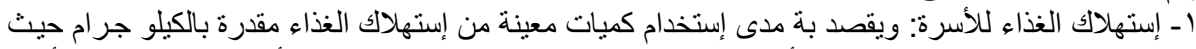

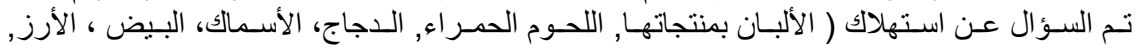

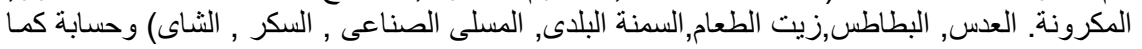
شهريا ثم سنويا.

r- نمط إستغلال الأرض الزيا.

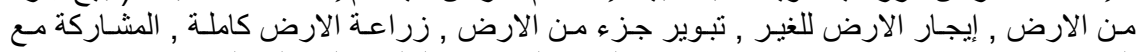

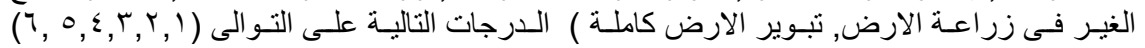

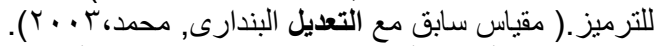

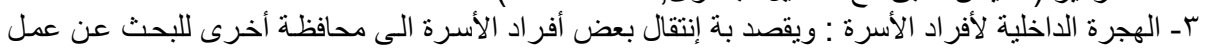

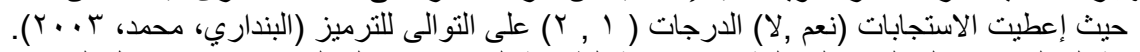

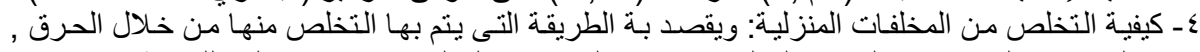

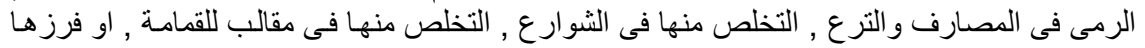

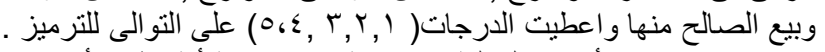

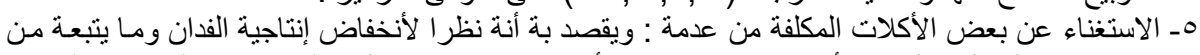

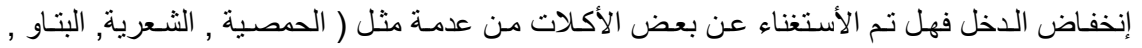

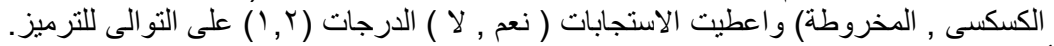

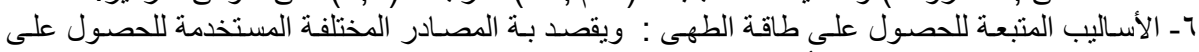

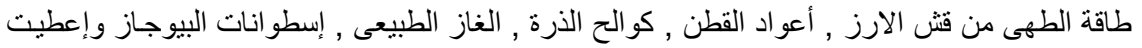

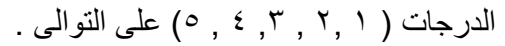

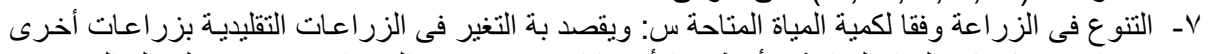

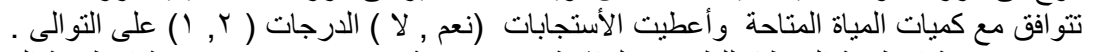

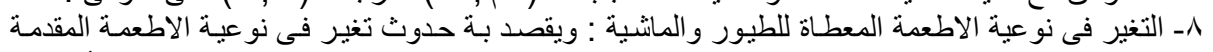

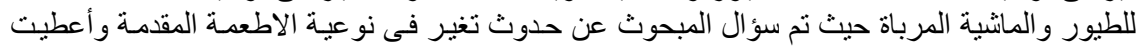

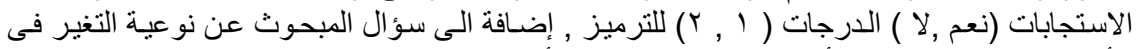
الأطعمة من خلال معرفة الأطعمة الجديدة المقدمة و الأطعمة التى تم حزفيز التها.

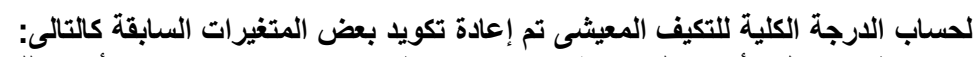

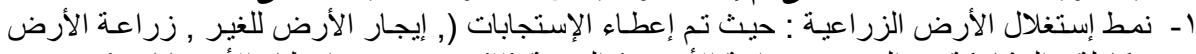

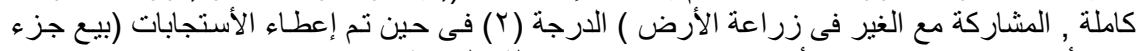

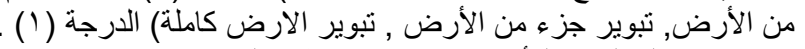

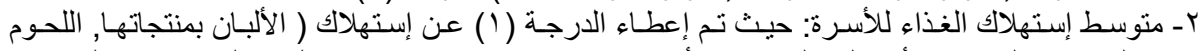

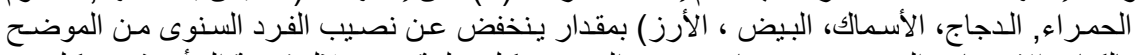

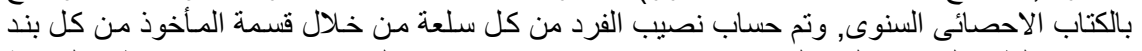

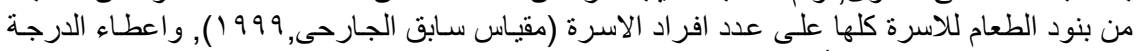

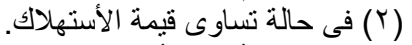

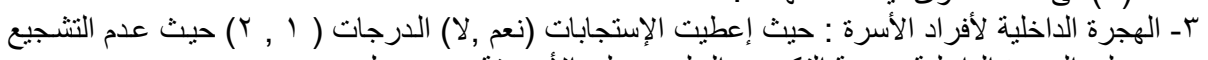

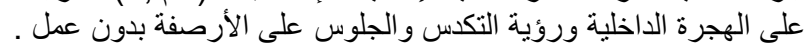


El Said, Mervat S. A.

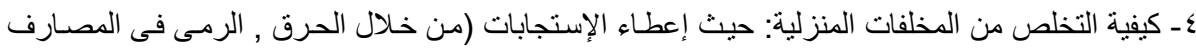

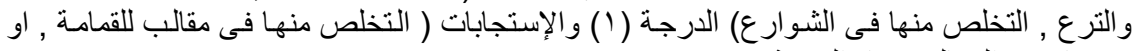

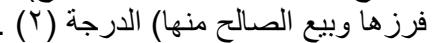

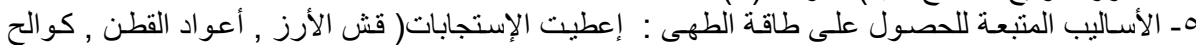

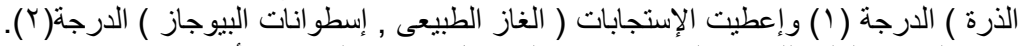

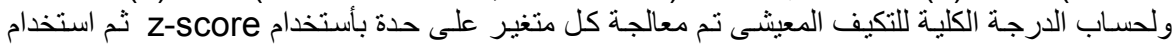

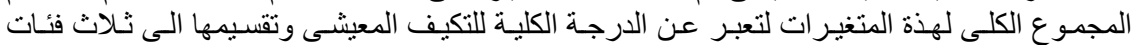

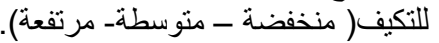

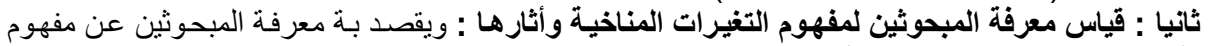

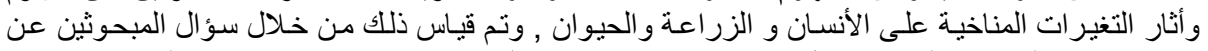

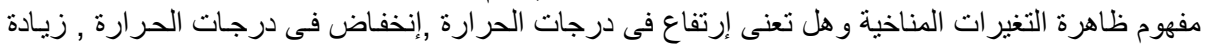

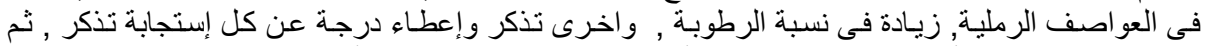

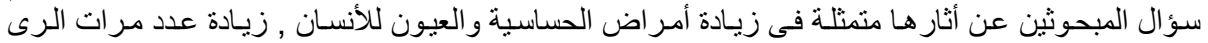

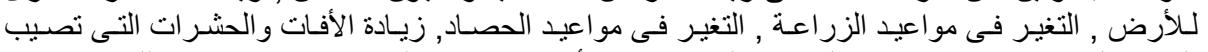

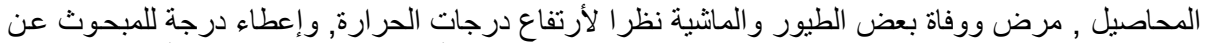

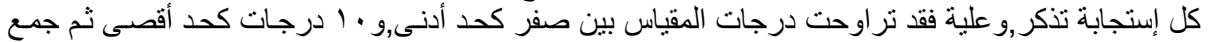

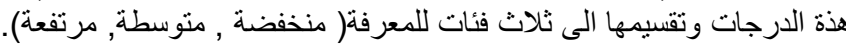

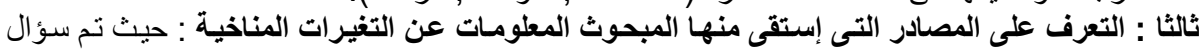

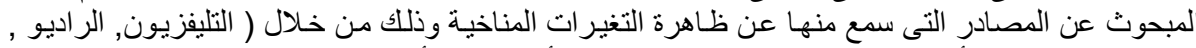

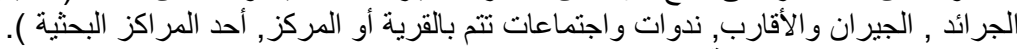
رابعا: متغيرات وصف عينة البحث:

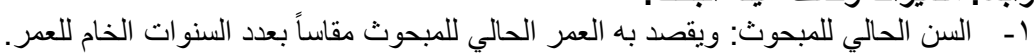

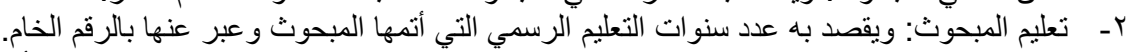

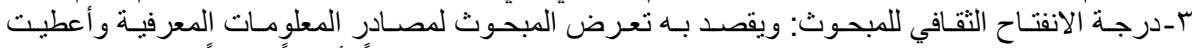

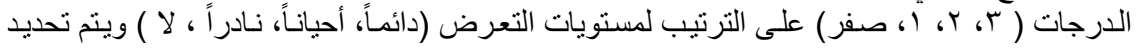

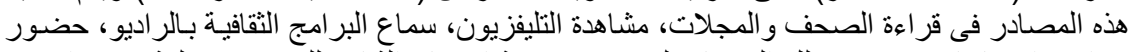

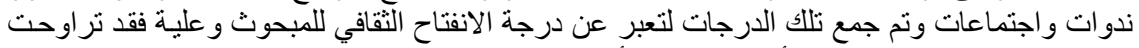

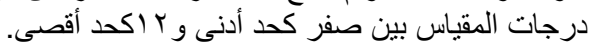

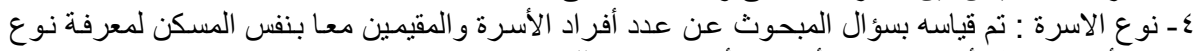

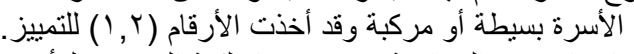

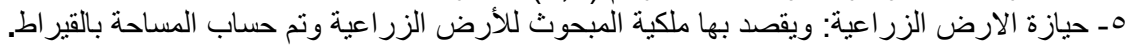

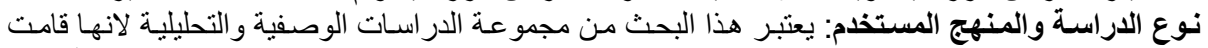

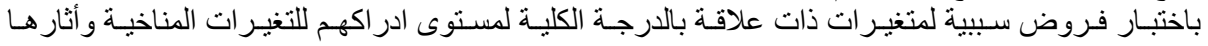

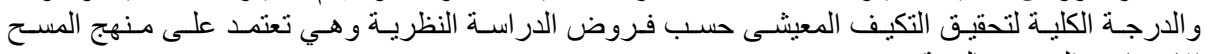
الاجتماعي الجزئي بالعينة.

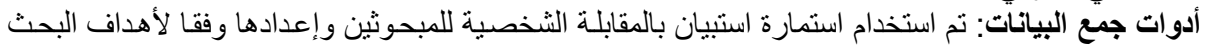

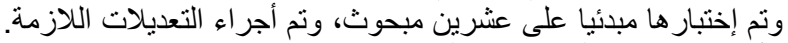

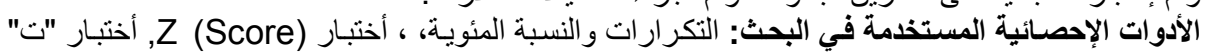
لالفرق بين متوسطين. وصف عينة البحث: تثبير البيانات الواردة بجدول ( ) () الى توزيع المبحوثين وفقا للسن الحسالى الى ان أكثر

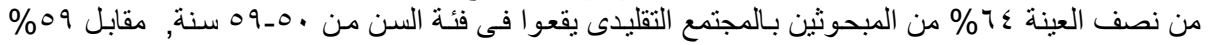

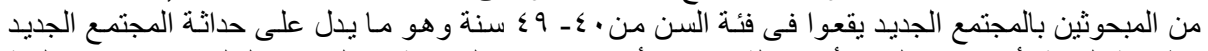

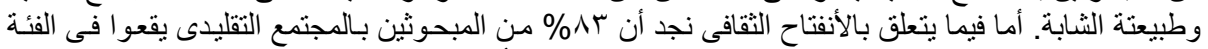

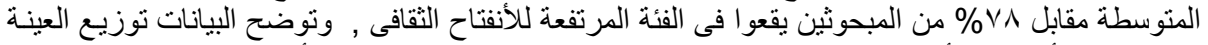

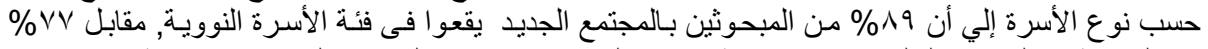

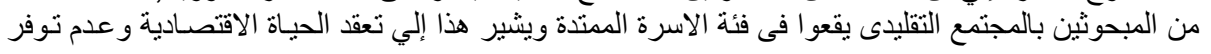




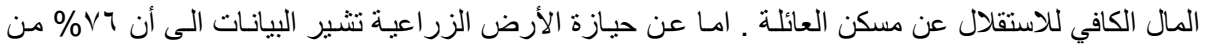

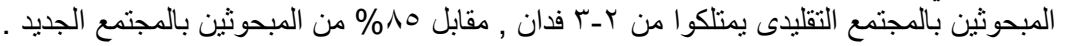

جدول( ('): توزيع المبحوثين وفقا لبعض خصائصهم التى تناولها البحث

\begin{tabular}{|c|c|c|c|c|}
\hline \multicolumn{2}{|c|}{ المجتمع الجديد } & \multicolumn{2}{|c|}{ المجتمع التقليدى } & \multirow[t]{2}{*}{ المتغيرات/نمط المجمتع } \\
\hline$\%$ & عدد & $\%$ & عدد & \\
\hline & & & & النس الحالى \\
\hline$r$. & rᄉ & 10 & 10 & . r- \\
\hline 09 & 09 & Y) & YI & . - \\
\hline \multirow[t]{2}{*}{$r$} & $r$ & $7 \varepsilon$ & $7 \varepsilon$ & .99_0.09 سنة \\
\hline & & & & تعليم المبحوث \\
\hline$\cdot$ & $\cdot$ & $\varepsilon$ & $\varepsilon$ & امى |م \\
\hline$r$ & $r$ & 1. & $\Lambda$. & |بتدائي \\
\hline 10 & 10 & $\cdot$ & $\cdot$ & |إعدادي \\
\hline rA & rA & 1. & 1. & تانوي \\
\hline \multirow[t]{2}{*}{$\leqslant 0$} & «o & 7 & 7 & عالي \\
\hline & & & & لرجة الانفتاح الثقافى \\
\hline V & $V$ & $1 \%$ & 14 & منخفض \\
\hline 10 & 10 & NT & NT & متوسط \\
\hline \multirow[t]{2}{*}{$V \wedge$} & $V \lambda$ & $\varepsilon$ & $\varepsilon$ & مرتفع \\
\hline & & & & لوع الاسرة \\
\hline 19 & 19 & rT & rT & نووية \\
\hline \multirow[t]{3}{*}{11} & 11 & $V V$ & $V V$ & متدة \\
\hline & & & & حيازة الارض \\
\hline & & rT & rT & |قل من فدان \\
\hline 10 & 10 & $V 7$ & $\mathrm{VT}$ & r T Tدان \\
\hline 10 & 10 & 1 & 1 & |ح فأكثرفدان \\
\hline
\end{tabular}

\section{النتائج ومناقشتها}

أولا : التعرف علي درجة معرفة المبحوثين بالأسرة الريفية لمفهوم التغيرات المناخيـة والأثار الناتجـة عن بمنطقتى الدراسة.

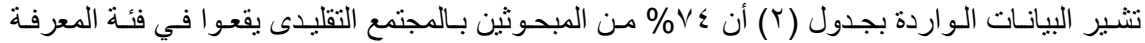

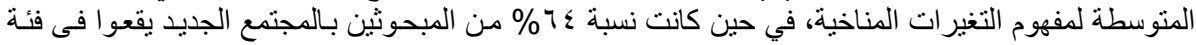

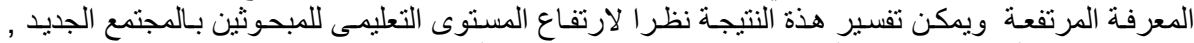

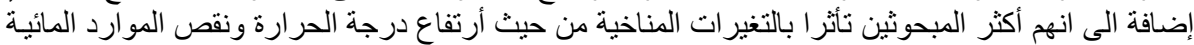

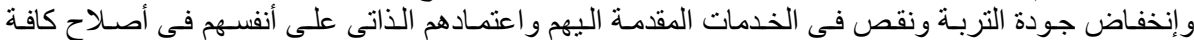

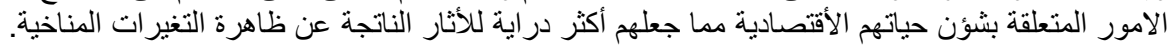

جدول رقم (Y): توزيع المبحوثين وفقا لدرجة معرفتهم بالتغيرات المناخية

\begin{tabular}{|c|c|c|c|c|}
\hline \multicolumn{2}{|c|}{ المجتمع الجديا } & \multicolumn{2}{|c|}{ ألمجتمع التقليدى } & الفئات / نمط المجتمع \\
\hline$\%$ & عدد & $\%$ & عدد & \\
\hline Y) & YI & $\pi$ & $\pi$ & منخفضة ·- ــ درجة \\
\hline$r$. & $r$. & $\mathrm{v \varepsilon}$ & $\overline{v \varepsilon}$ & تتوسطة من 0 ـ 9 درجة \\
\hline $7 \varepsilon$ & $7 \varepsilon$ & ir & ir & مرتفعة ، ( فأكثر درجة \\
\hline $1 \ldots$ & $1 \ldots$ & $1 \ldots$ & $1 \ldots$ & الاجمالى \\
\hline
\end{tabular}

المصدر: جمعت وحسبت من استمارات الاستبيان

ثانيا : تحديد معنوية الفروق بين المبحوثين فيمـا يتعلق بالدرجة الكلية لمعرفتهم بـالتغيرات المناخية والأثار الناتجة عنها بمنطقتى الاراسة: 
El Said, Mervat S. A.

ينص الفرض الاحصائى على " عدم وجود فروق معنوية بين المبحوثين فيما يتعلق بالدرجة الكلية

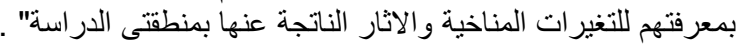

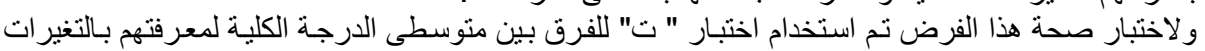

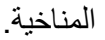

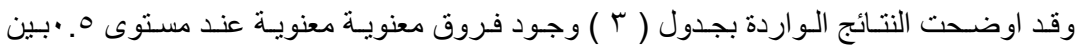

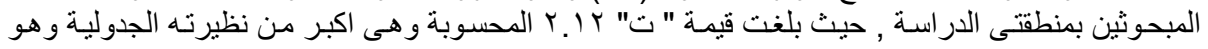

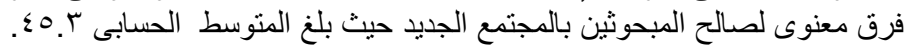

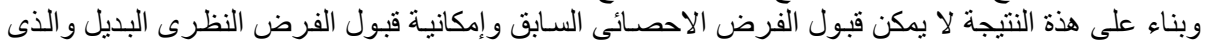

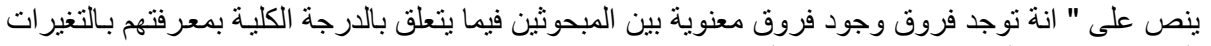

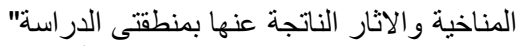

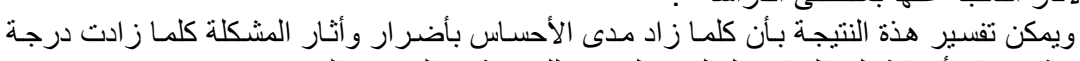

معرفة المبحوثين بها , أضافة الى الجانب التعليمى المرتفع للمبحوثين بالمجتمع الجديد.

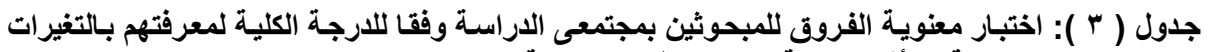
المناخية والأثار الناتجة عنها بمنطقتى الدراسية

\begin{tabular}{|c|c|c|c|}
\hline قيمة"ت & الأتحر اف المعيارى & المتوسط الحسابي & |الفئات \\
\hline \multirow[t]{2}{*}{ *Y.IT } & I. & $\varepsilon \cdot .1$ & المبحوثين بالمجتمع التقليدى \\
\hline & V.YO & $\varepsilon 0 . r$ & المبحوثين بالمجتمع الجديد \\
\hline
\end{tabular}

ثالثا : التعرف علي درجة التكيف المعيثى للمبحوثين للحد من الأثار الناتجة عن التغيرات المناخية بمنطقى

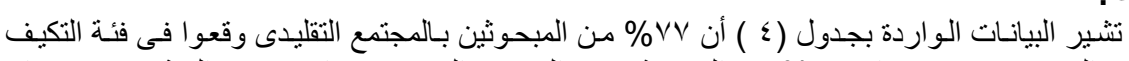

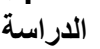

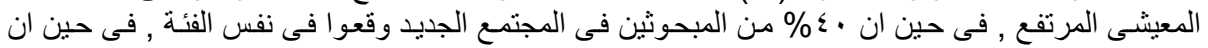

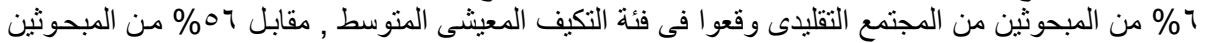

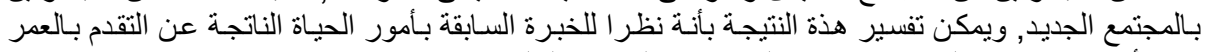

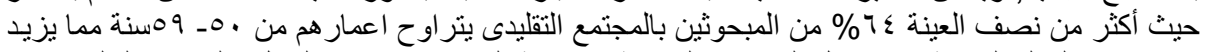

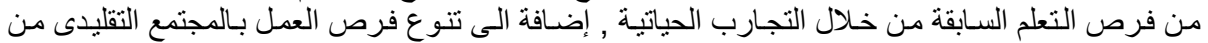

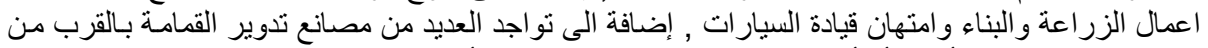

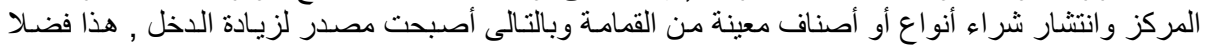
عن عدم تبوير الارض كما فعل المبحوثين بالمجتمع الجديد.

رابعا: تحديد معنوية الفروق بين المبحوثين فيما يتطلق بالدرجة الكلية للتكيف المعيثى للعد من الأثار الناتجة عن التغيرات المناخية بمنطقتى الاراسة.

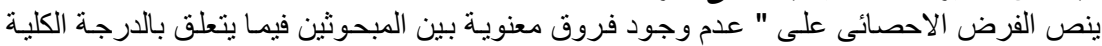

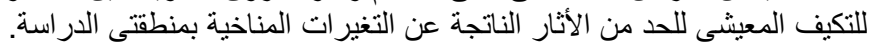

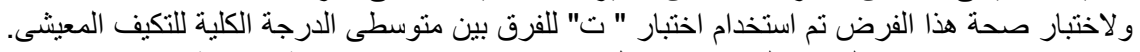

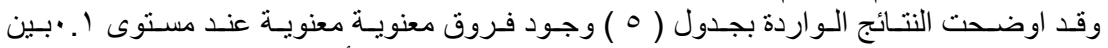

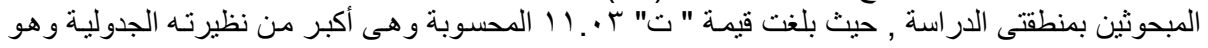

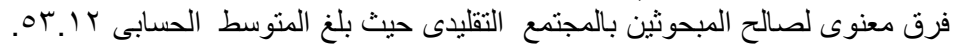

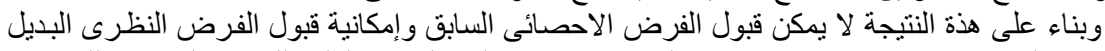

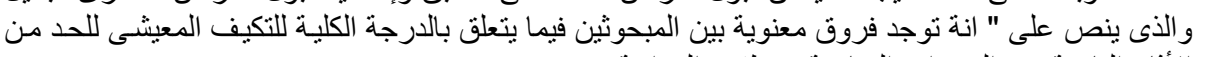

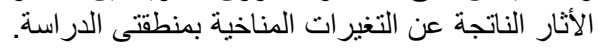

جدول رقم (؛): توزيع المبحوثين وفقا لارجة التكيف المعيشى النئي

\begin{tabular}{|c|c|c|c|c|}
\hline \multicolumn{2}{|c|}{ المجتمع الجديا } & \multicolumn{2}{|c|}{ المجتمع التقليدى } & |الفئات/نمط المجتمع \\
\hline$\%$ & عدد & $\%$ & عدد & التكيف المعيشى \\
\hline$\varepsilon$ & $\varepsilon$ & TV & TV & 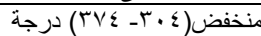 \\
\hline 04 & 07 & 7 & 7 & متوسط (rV0_ _ ؛ ؛) درجة \\
\hline
\end{tabular}




\begin{tabular}{|c|c|c|c|c|}
\hline$\varepsilon \cdot$ & $\varepsilon \cdot$ & VV & VV & مرتفع (ד ؟ ؟ فاكثر) درجة \\
\hline$\ldots$ & $1 \ldots$ & $1 \cdots$ & $1 \cdots$ & الاجمالى \\
\hline
\end{tabular}

جدول ( • ): اختبار معنوية الفروق للمبحوثين بمجتمعى الدراسة وفقا للارجة الكلية للتكيف المعيشى الانى

\begin{tabular}{|c|c|c|c|}
\hline ققيمة"ت" & الأتحراف المعيارى & المتوسط الحسابى & الفئات \\
\hline \multirow[t]{2}{*}{$* * 11 . \cdot r$} & YA. ${ }^{\prime}$ & Or.Ir & المبحوثين بالمجتمع التقليدى \\
\hline & $r \varepsilon . r$ & TA.YT & المبحوثين بالمجتمع الجديد \\
\hline
\end{tabular}

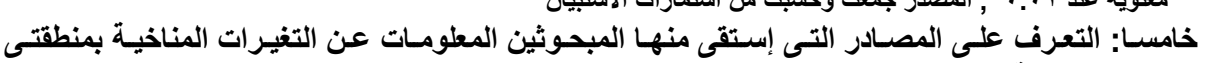

$$
\text { الدراسة. }
$$

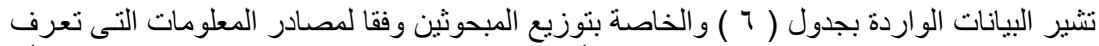

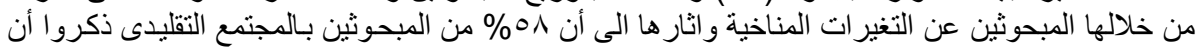

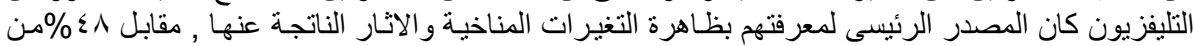

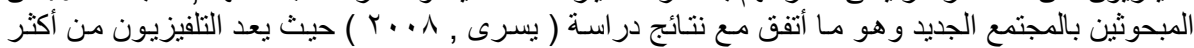

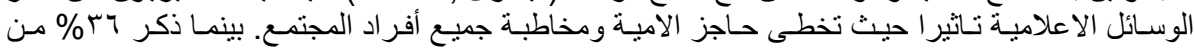

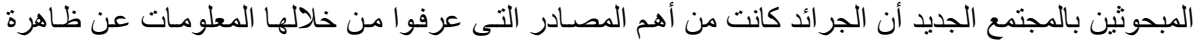

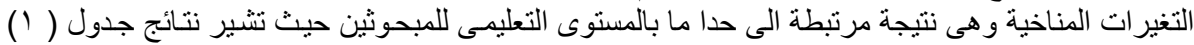

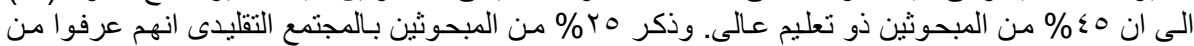

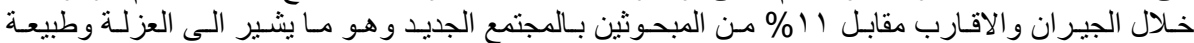

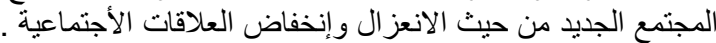

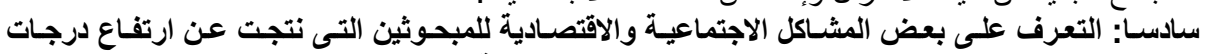

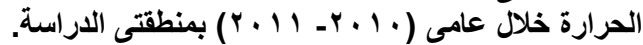

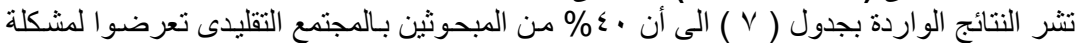

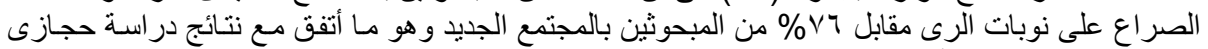

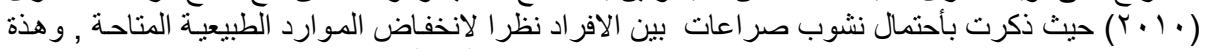

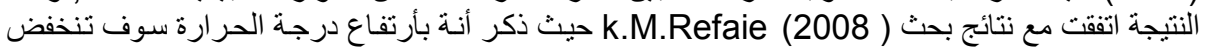

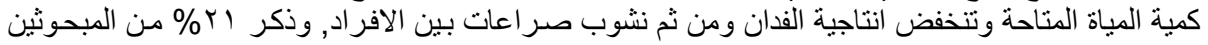

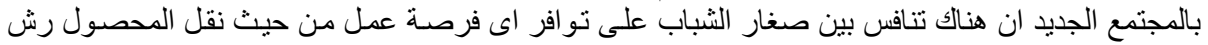

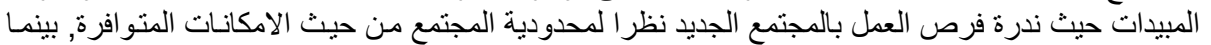

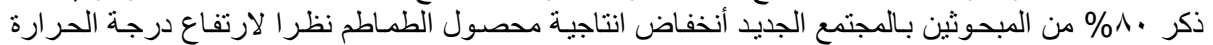

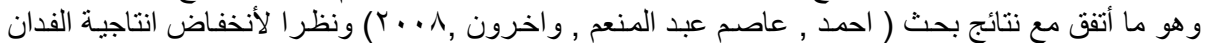

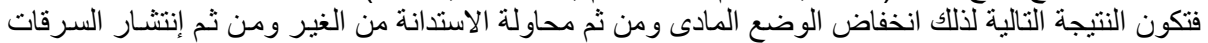

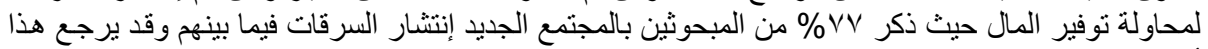

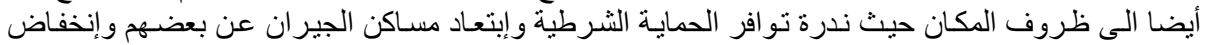

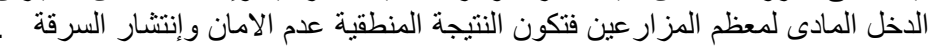

جدول († ): توزيع المبحوثين وفقا لمصادر المطومات التى إستقى منها المبحوثين المعلومـات عن التغيرات

\begin{tabular}{|c|c|c|c|c|}
\hline$\%$ & (التكرئ الجديد) & $\%$ & ( المجتمع التقليدى) & المصدر/ نمط المجتمع \\
\hline$\sum \lambda$ & 9. & 01 & 90 & |التليفزيون \\
\hline$r 4$ & $V \cdot$ & IV & YA & |لجر ائد \\
\hline 11 & rI & To & §1 & |لجير ان و الاقارب \\
\hline$r$ & $\varepsilon$ & $\cdot$ & $\cdot$ & لدو ات واجتماعات \\
\hline$\because 0$ & 1 & $\cdot$ & $\cdot$ & |حد المر اكز البحثية \\
\hline$\cdot$ & $\cdot$ & $\cdot$ & $\cdot$ & |المرشدين الزر اعين \\
\hline
\end{tabular}


El Said, Mervat S. A.

جدول ( V ) : توزيع المبحوثين وفقا لبعض المثاكل الاجتماعية والاقتصادية للمبحوثين التى نتجت عن

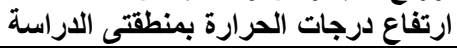

\begin{tabular}{|c|c|c|c|c|}
\hline$\%$ & عداد(المجتمع الجديد) & $\%$ & عداد(المجتمع التقليلياى) & المشكلات الاجتماعية والاقتصادية \\
\hline $\mathrm{V} 7$ & $V \Upsilon$ & $\varepsilon$. & $\varepsilon$ & الصر اعات بين الجيران على نوبـات \\
\hline . & . & 7 & 7 & الحامعة قدرة الفنيات على الذهاب الـى \\
\hline Y) & rI & 10 & 10 & الى فرصر عمل بئلار الثباب على تو افر \\
\hline$r$ r. & $r$ r. & . & $\Lambda$ & يرك الكثير من الارض بور \\
\hline A. & A. & . & . & انخفاض انتاجية محصول الطماطم \\
\hline$\varepsilon$ & $\varepsilon$ & . & . & غلق بعض المنازل و الذهاب عند الاهل \\
\hline 9 . & 9. & $\Gamma \xi$ & $r \varepsilon$ & 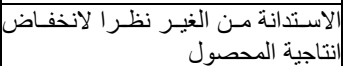 \\
\hline$\overline{V V}$ & VY & 11 & 11 & انتشار السرقات للمو اشى والمنازل \\
\hline
\end{tabular}

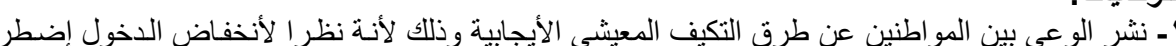

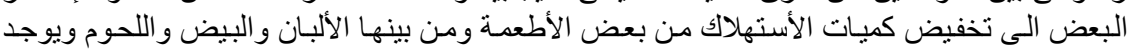

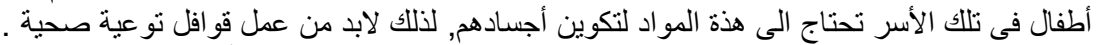

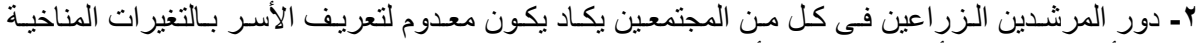
و أضرارها حيث أظهرت البيانات أسن المصدر الرئيسى لمعلوماتهم من خلال التليفزيون.

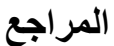

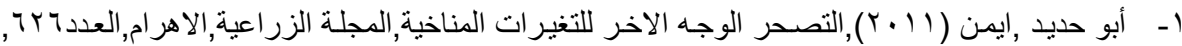
جمهورية مصر العربية.

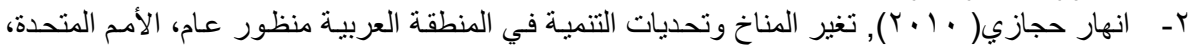

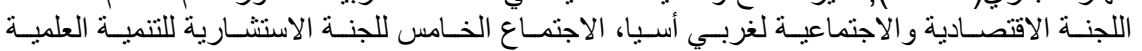

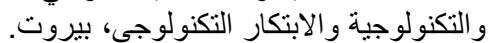

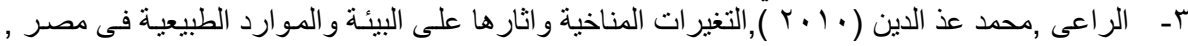

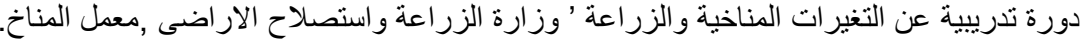

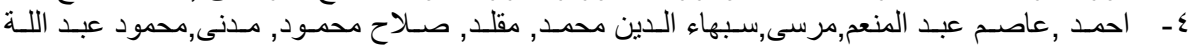

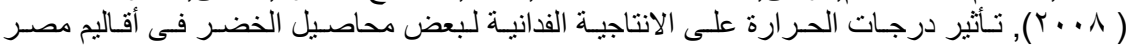

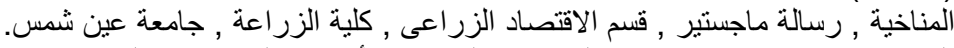

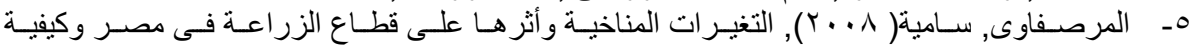

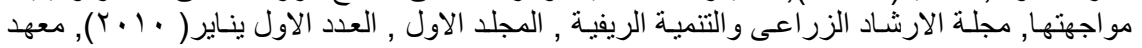

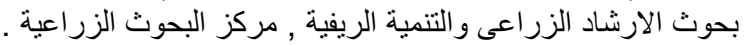

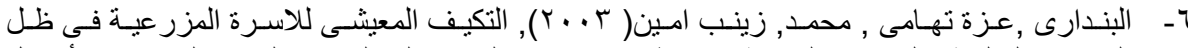

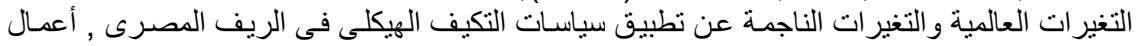

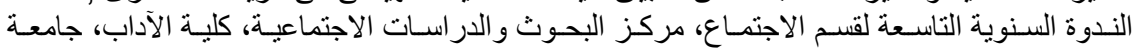

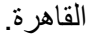

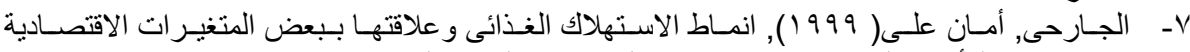

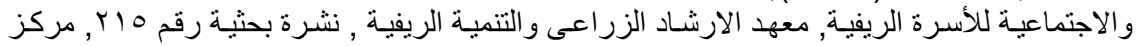

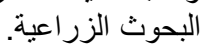

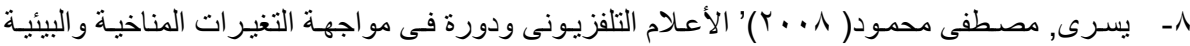

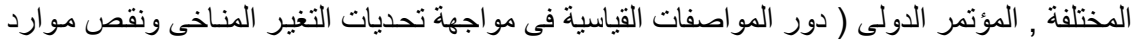

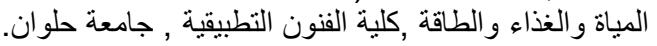

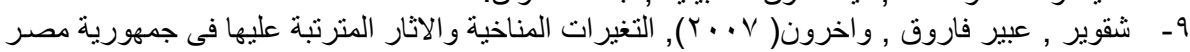
العربية , مركز المعلومات ودعم اتخاذ القرار , مجلس الوزراء. 


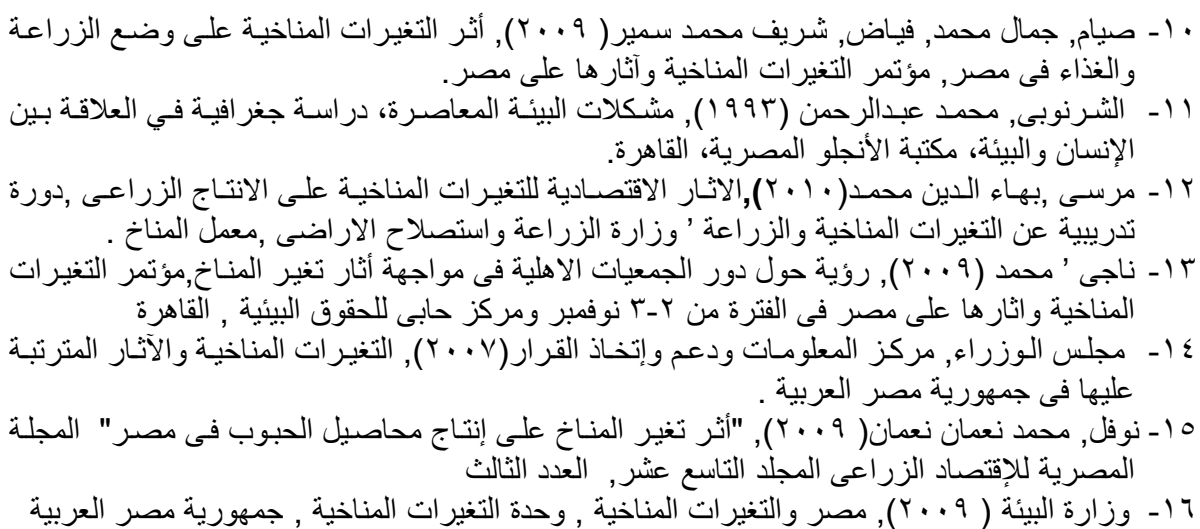

1- K.M.Refaie,S.A.Shanan,A.A.Mohmed, 2008,impact of climate changes on water balance of potato crop ,Nin international conference on dryland development , Alexandria ,Egypt

2- Collins, W., et al. 2007. Climate change. Scientific Am. 64: 65-73. Courtlier, V., and D.J. Stanley. 1987. Late Quaternary strategraphy and paleogeography of the eastern Nile Delta, Egypt. Marine Geology.27: $257-275$.

3-Tille, I.A.1987, family strategies, hits.Meth.No(20 -3

4-Krekcie, Roberts Morgan, daryle, 1970 , determining sample size research activates in educational and psychological measurement college station, Durham, north. Carolina, U.S.A, vol (30).

\section{A COMPARATIVE STUDY OF THE RURAL FAMILY LIVING ADAPTATION WITHIN THE FRAME WORK OF CLIMATE CHANGE IN A NEWLY RECLAIMED AND COMMUNITY AND A TRADITIONAL COMMUNITY IN MINYA GOVERNORATE El Said, Mervat S. A. \\ rural woman Dept., Agric. Extension and Rural Development Res. inst.}

\section{ABSTRACT}

The study aimed to identifying the The degree of knowledge of respondents about concept of climate change and its impact, testing significance differences among the respondents concerning the degree of knowledge of climate change, identifying the degree of living adaptation of the respondents and Testing significance differences, sources of the information, finally some of the social and economic problems.

The study was conducted on mania Governorate based on percentage of the high and low temperatures during the five years as a component of climate change. 
El Said, Mervat S. A.

Data were collected from sample of 200 head of households from "El ghad" village representing the new community, and " El msed" village representing the traditional community by

using personal interview a questionnaire, the following statistics methods were used in data analysis simple "t" test, and test $Z$ (score), frequencies percentages. The most important results of the analysis as follows:

1 - the level of knowledge traditional community interviewees located in middle pattern of climate change, while the respondents located in higher pattern from the new community

2- There is a difference between respondent on 0.5 level according to the total degree of knowledge of climate change and its effects.

$3-77 \%$ of the respondents of the traditional society located in higher level of living adaptation of category, while $56 \%$ from respondents on new community located in middle category, there was a significant difference between respondents at 0.1 .

كلية الزراعة - جامعة المنصورة الزية
قام بتحكيم البحث

أ.د / محمد السيد الامام

أ.د / حسن احمد مصطفى الامئ 